\section{- Publicaciones}

Pretende localizar la atención sobre escritos cinematográficos cuyo objetivo primordial sea dar a conocer las plurales visiones de la Historia del Cine en Andalucía a través de la publicación de trabajos de investigación, ensayos o monografías. Ello no impide la edición de obras de interés relacionadas con el Cine Español, con otras cinematografías y con la comunicación audiovisual en general

\section{- Cuadernos Filmoteca}

Pretende, a manera de dossiers informativos, difundir algunas de las actividades audiovisuales llevadas a cabo en nuestra Comunidad Autónoma

\section{Proyectos de futuro}

Las principales líneas de actuación de la Filmoteca de Andalucía con la nueva Dirección están encaminadas a cumplir un objetivo general: ampliar y reforzar la presencia de la Filmoteca de Andalucía en todas las provincias de Andalucía, así como en todos aquellos foros propios de un archivo específico como la Filmoteca. El plan de actuaciones contempla:

- Creación de una campaña de localización de material cinematográfico que abarque todo el ámbito geográfico de la Comunidad Autónoma

- Formación de técnicos para la búsqueda y tratamiento de materiales

- Contacto con los principales agentes, empresas e instituciones del sector para el conoci- miento y actuación de todas aquellas producciones realizadas por andaluces o en Andalucía, tanto en presente como en pasado

- Normalización, sistematizacion y seguimiento del Depósito Legal

- Establecimiento de sistemas de seguridad de los fondos

- Eliminación de barreras arquitectónicas y ampliación de las instalaciones.

- Creación de ayudas a la investigación en materias relacionadas con el Patrimonio Histórico Audiovisual Andaluz

- Solicitud de la inclusión de la Filmoteca de Andalucía en la Federación Internacional de Archivos Filmicos

Pepa Díaz Dueñas

Responsable del Departamento de Documentación

\title{
Parques Naturales en Internet
}

Los itinerarios y rutas culturales están de moda en Internet. Tenemos ya a nuestro alcance la posibilidad de visitar una catedral, un yacimiento arqueológico, un museo, o bien, la alternativa de realizar una excursión por diferentes parajes históricos o emblemáticos de nuestra tierra o de la historia en general, como son , por ejemplo, las rutas que nos propone en su web el Legado Andalusí.

Del mismo modo, sin escaparse a la curiosidad del visitante y de gran interés en la actualidad, existe la opción no menos interesante que las anteriores de poder visitar los numerosos y todavía algo desconocidos Parques Naturales de nuestra región.

Traemos aquí a análisis algunos ejemplos interesantes de sitios dedicados a mostrar los diversos contenidos que alberga un parque natural, analizado de diversas formas y con distinta profundidad.

En primer lugar, cabe destacar en la Sede Web dedicada a la provincia de Cádiz: www.cadiznet.com, la entrada que le dedica a sus Espacios Naturales: Parques, Reservas y Parajes. De entre sus Parques destacan el Parque Natural de la Sierra de Grazalema, el Parque Natural del entorno de Doñana, el Parque Natural del Acantilado y Pinar de Barbate y finalmente, el Parque Natural de la Bahía de Cádiz. Sobre todos ellos encontramos una página que nos muestra sólo datos muy básicos pero esenciales de cada parque en concreto: Geografía (entorno físico que ocupa), flora y fauna, así como recursos económicos que genera, para terminar con una ficha técnica con datos sobre la superficie que ocupa, el número de habitantes con los que cuenta y su clasificación, es decir, el año en que ese espacio fue declarado parque natural. Todas las páginas van acompañadas de una imagen característica de cada espacio natural reseñado.

Sobre el ultimo parque señalado, Parque Natural de la Bahía de Cádiz, existe una sede específica denominada Asociación de amigos del Parque Natural "Bahía de Cádiz", que aunque aún se encuentra en fase de construcción cuenta con unos interesantes apartados, de los que hoy sólo dos están operativos. Son apartados dedicados a la Organización de la Asociación, Historia, Nuestro Parque, Fines de la Asociación, Altas de nuevos socios, Noticias y Actividades.

Los que actualmente tienen desarrollado algún contenido son por un lado el dedicado a Nuestro Parque, que cuenta con información sobre el entorno natural en el que se encuentra, su geoestructura, la estructura de su salina, sus especies piscícolas y su avifauna y la flora así como datos sobre la historia y tradiciones de sus comarcas, acompañados de imágenes sobre distintas zonas del parque; y por otro lado tenemos el apartado dedicado a Altas con un formulario para aquellos que deseen formar parte de la Asociación.

En segundo lugar, y con otro nivel de tratamiento más profundo y exhaustivo tanto en los datos descriptivos como en el análisis de sus pueblos y rutas, traemos como ejemplo la Sede dedicada al Parque Natural Sierra Norte de Sevilla.

En ella encontramos un menú principal a través del cuál y situándonos con el ratón encima de cada uno de ellos se despliega un submenú.

De esta forma el mapa del web queda resuelto de la siguiente manera:

Noticias: Actualidad y Eventos.

El Parque: Mapas, Alojamientos y Rutas. Los Pueblos: Historia, Monumentos y El Pueblo Hoy.

Visitas: Fotos del Parque y Actualidad Gráfica.

Comenzando por el apartado dedicado a Noticias, dentro de Actualidad, encontramos una selección de las últimas noticias de actualidad que resultan de interés para la comarca tales como celebraciones de ferias, creación de nuevas líneas férreas, talleres, etc., con una breve descripción de la noticia o el acontecimiento en cuestión. 


\section{FICHA DE LA WEB}

\begin{tabular}{ll}
\hline URL PRINCIPAL & http://www.sierranortedesevilla.com \\
\hline TITULAR & Página diseñada por Neuronet Networks s.l. \\
\hline INFORMACIÓN DISPONIBLE & Muy Buena(variada y útil) \\
\hline CALIDAD GRÁFICA & Buena \\
\hline DISEÑO WEB & Medio \\
\hline FACILIDAD DE NAVEGACIÓN & Buena \\
\hline VELOCIDAD DE CARGA & Rápida \\
\hline ACTUALIZACIÓN & Buena (presenta la fecha del día en curso) \\
\hline CALIDAD GLOBAL & Buena
\end{tabular}

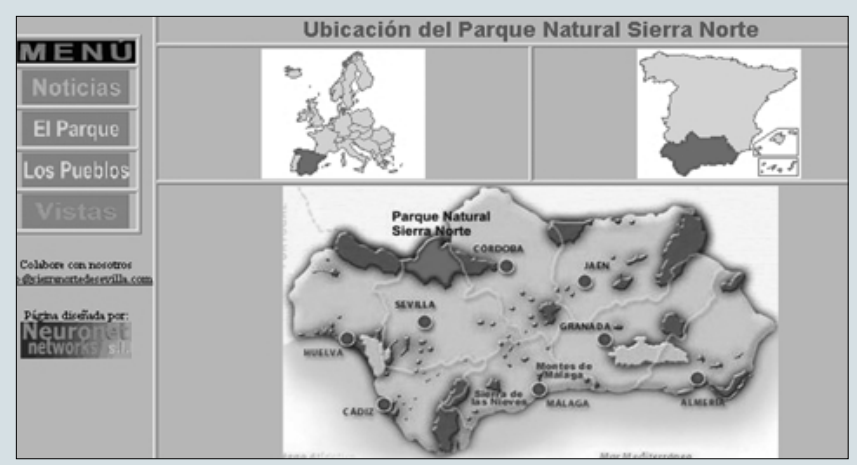

Del mismo modo, dentro de Noticias en el apartado Eventos, encontramos reseñas y datos concretos sobre las actividades $y$ ferias actuales de un pueblo o que tendrán lugar durante el verano.

Estos apartados son de gran actualidad y se actualizan a la medida de las nuevas noticias que surgen o los eventos que están próximos a desarrollarse.

Ya dentro del apartado dedicado al Parque, encontramos un primer subapartado denominado Mapas. Es este un elemento esencial para situar el parque dentro de la geografía andaluza. y para que los visitantes se orienten a la hora de decidir visitarlo. Es por tanto uno de los mejor resueltos y más relevantes para incitar al público a conocerlo.

En primer lugar, aparece un mapa de la situación del parque dentro de Europa y de España, para luego ir concretando su ubicación dentro de Andalucía. Posteriormente aparece un mapa con la situación de todos los municipios que engloba: Alanís, Almadén, Cazalla, Constantina, Guadalcanal, Navas de la Concepción, Pedroso, Puebla de los Infantes, Real de la Jara y San Nicolás del Puerto.

Continuamos con un mapa que sitúa a los municipios dentro de la red de caminos, seguido de otro que orienta al visitante sobre cómo llegar por carretera y finalmente, en tren.

Todos los mapas están desarrollados con una excelente calidad gráfica e informativa.

Siguiendo con el submenú del El Parque, encontramos un completo listado de Alojamientos (hoteles, alojamientos rurales, etc) por pueblos, indicando su categoría, dirección y teléfono.
Terminamos el recorrido dentro de El Parque con el apartado dedicado a Rutas ya preestablecidas e indicadas en longitud y tiempo de recorrido, y que suponen un elemento básico a la hora de emprender una visita. Estas rutas son las denominadas: Por el corazón de la Sierra Norte, con $290 \mathrm{Km}$. de extensión y seis horas de duración; Camino de las Laderas, con $5 \mathrm{Km}$. de longitud; Camino Viejo, 4 Km; Sendero del Pico Hamapega, con tres horas de ida; Contraembalse del retortillo, 3 horas de ida; Sendero de los Castañares con una hora y media de duración y Camino de la Ermita de Belén. En todas las rutas se indica el grado de dificultad que presenta, la mejor época del año para realizarla, así como los pueblos que están implicados en la misma. Asimismo, están muy bien descritos los caminos a seguir.

El siguiente apartado de sumo interés para completar el conocimiento en profundidad de la comarca es el que está dedicado a Los Pueblos.

Dentro de éste, encontramos un menú desplegable con cada uno de los pueblos anteriormente relacionados y la posibilidad de ver su historia o pasear por sus monumentos, con un amplio recorrido formal y estilístico. Igualmente encontramos un apartado dedicado a El Pueblo Hoy con datos sobre accesos y comunicaciones por carretera, en tren y autobús, así como alojamientos y fiestas, $y$ un apartado de ofertas complementarias como rutas a caballo, áreas recreativas, deportes acuáticos, pesca o caza entre otros. Finalmente se muestra una lista de bares $y$ restaurantes recomendados y lugares de interés dentro del entomo urbano de cada pueblo.

Para finalizar con los grandes bloques de contenido, tenemos el dedicado a las Visitas, dentro del cual encontramos una página con una amplia galería de Fotografias del Parque, de su artesanía, su paisaje y su fauna. Asimismo, en
Actualidad Gráfica, tenemos una selección de imágenes que muestran eventos o acontecimientos que han resultado de gran relevancia durante el año en curso en la comarca.

La página web cuenta además con un formulario para que el visitante plasme su opinión sobre la misma, bajo el título "¿Qué le parece nuestra Web?". Esta iniciativa ayuda a mejorar la interactividad con el usuario, a la vez que permite conocer de primera mano las posibles carencias de información.

En conclusión, la página web del Parque Natural Sierra Norte de Sevilla presenta un contenido muy útil y variado en cuanto a los posibles accesos al mismo, las rutas a seguir en su visita, los alojamientos y restaurantes recomendados, así como un amplio reportaje fotográfico del mismo y un apartado vivo donde se comentan las últimas novedades ocurridas en el entorno (fiestas y eventos varios). Todo ello acompañado como hilo conductor de un amplio y completo recorrido por todos los pueblos que lo conforman.

La navegación es sencilla, destacando principalmente el menú inicial con subopciones interiores, que siempre están presentes como guía, la calidad y rigor de sus mapas y la valida aunque no por ello demasiado extensa información que ofrece.

Existen infinidad de sedes de Parques Naturales en Internet, como también existen infinidad de formas de presentarla. He aquí un ejemplo muy completo de uno de ellos para que sirva como punto de partida para el descubrimiento de nuevos parajes y lugares, que desde Internet, nos ayuden a conocer mejor nuestro entorno más natural.

Susana Limón Rodríguez Centro de Documentación del IAPH 